\author{
Didier Payen \\ Karim Asehnoune \\ Hans Dieter Volk
}

\section{Mucosal associated invariant T (MAIT) cell: a novel cellular mechanism participating in post-aggressive immunodepression}

Received: 18 November 2013

Accepted: 19 November 2013

Published online: 10 December 2013

(C) Springer-Verlag Berlin Heidelberg and ESICM 2013

D. Payen $(\bowtie)$

Service d'Anesthésie-Réanimation-SMUR, Lariboisière AP-HParis, Université Paris Diderot-Paris 7, 75010 Paris, France e-mail: dpayen1234@orange.fr

\section{K. Asehnoune}

Service d'Anesthésie Réanimation, Nantes University Hospital Hôtel-Dieu, Nantes, France

H. D. Volk

Berlin-Brandenburg Center for Regenerative Therapies (BCRT), Institute for Medical Immunology, Charité-Universitätsmedizin Berlin, Berlin, Germany

The long list of failures of high-profile clinical trials on sepsis has led researchers to state that sepsis studies need a new direction that is based on the pathophysiological mechanisms operating in sepsis [1]. Among these mechanisms, the concept of immunodepression has emerged and would seem to have a central role, as recently reviewed [2]. This has been substantiated by clinical results [3-6]. Early immunodepression involves both innate and adaptive immunity [7] with a reduction in monocyte human leukocyte antigens (HLA)-DR expression [4, 6], "exhaustion" of $\mathrm{T}$ cells with induced apoptosis and reduced functional activity of almost all T-lymphocyte subsets [2], with the exception of CD25(+)Fox(-)P3(+) T lymphocytes [8]. As a consequence, the resolution of the initial infection might be impaired with high risk of development of secondary infections.

The article by Grimaldi et al. published in this issue of Intensive Care Medicine [9] describes an alteration in a new subset of cells as an important mechanism for multifactorial induced immunodepression. These authors describe an early decrease in the level of blood mucosalassociated invariant T (MAIT) cells in a cohort of 156 intensive care unit (ICU) patients relative to MAIT cell number in healthy controls. This reduction in MAIT cell number was observed mainly in septic patients but also in ICU non-septic patients and was associated with the prevalence of secondary infection, but was not associated with other innate-like lymphocyte populations [natural killer cells (NKT) and $\gamma \delta$ T cells].

In 1993, two distinct a $\beta$ T-cell receptor (TCR) T-cell populations were identified that express the semi-invariant $\alpha$-chain [10]. Further analysis led to the description of two "innate" human T-cell populations: MAIT cells [11] and NKT cells. At least two distinct subsets of MAIT cells have been identified, both of which express a TCR that is associated with MAIT cells: one subset of MAIT cells has an immunomodulatory role, as shown in multiple sclerosis [12], and the other subset of MAIT cells is activated by host cells infected with microorganisms [13]. This latter subset [restricted MAIT (MR1) cells] detects the non-polymorphic antigen-presenting molecule major histocompatibility complex (MHC) class I-related protein 1 (MR-1). In a recent review on MR1 cells [14], the authors mention that is only recently $[13,15]$ that the in vivo role of MAIT cells as a detector of infection has been demonstrated. Almost all microorganisms, with the exception of viruses, Streptococcus spp. and Listeria monocytogenes, may stimulate MAIT cells, which in turn produce interferon gamma, tumor necrosis factor, interleukin-17 and granzyme, all crucial mediators for controlling intracellular infection. It has been noted that only microorganisms that can synthesize riboflavin seem to have the MAIT-stimulating capacity, a finding consistent with the observation that riboflavin metabolites bind MR1 and result in MAIT cell activation. Despite similarities between antigen-presenting molecules of 


\section{MAIT cells activation}

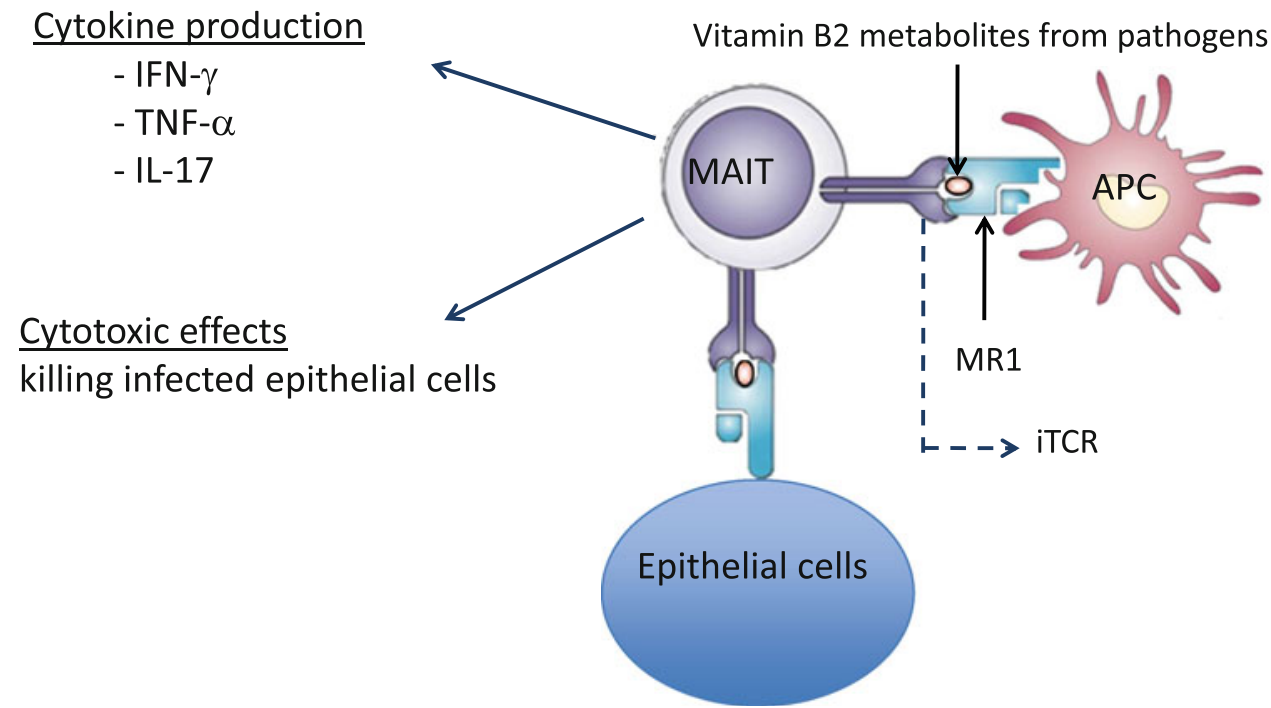

Fig. 1 Model of mucosal-associated invariant T (MAIT) cells activation (reprinted from [16] with permission). MAIT cells sense pathogens through an invariant T-cell receptor (iTCR) molecule expressed at their surface. The iTCR molecule recognizes vitamin B2 metabolites from pathogens binding to the major histocompatibility complex (MHC) class I-related molecule restricted MAIT (MRI)

MHC class Ia and MR1, there are also differences as MHC class Ia molecules present peptide ligands, whereas MR1 can bind pterin analogs [14]. MAIT cells have both innate and adaptive features that focus attention on the role of MAIT cells in the recognition of microbial infection. If the development of an immunologic memory distinguishes innate from adaptive immunity, it becomes important to determine whether MAIT cells have a memory or not-a question not yet resolved. A model for MAIT activation after a bacterial challenge is shown in Fig. 1.

The major inputs of the Grimaldi et al. [9] study are the observed reduction in MAIT cell number associated with prevalence of secondary infections in human beings which was not observed with other innate-like lymphocyte subsets, namely, the NKT and $\gamma \delta \mathrm{T}$ cells. The authors confirmed the previously shown non-response of MAIT cells to Streptococcus spp., L. monocytogenes and virus infection. The observed low number of blood MAIT cells may result from various mechanisms, and these require further investigation. Possible explanations for the observed decrease of MAIT cell number in blood from ICU patients may be: (1) cell recruitment in infected tissues, as shown in the mice model of mycobacteria, Escherichia coli and Klebsiella infections lacking MAIT cells, has been associated in infected animals with a worse outcome; (2) the drop in MAIT cell count could also be consecutive to an induced apoptosis
After recognition, MAIT cells kill infected epithelial cells. Activation of MAIT cells by antigen-presenting cells induces the production of interferon gamma $(I F N-\gamma)$, tumor necrosis factor alpha $(T N F-\alpha)$ or interleukin-17 (IL-17), which in turn improve both the adaptative and immune response

of MAIT cells, as shown for lymphocytes [2], as a part of the global immunodepression phenomenon [2]. The described decrease in MAIT cells in patients during secondary infection can be a cause or consequence, a concept that needs further investigation. By analogy with monocytic expression of HLA-DR, it is more likely that the non-recovery of MAIT cell number-rather than the amplitude of cell number reduction - which could be the factor favoring the occurrence of secondary infection in septic patients [6]. However, it has been shown that even if the HLA-DR expression has a positive slope to recover, the occurrence of a secondary infection once again induces a drop in HLA-DR expression. Whatever the mechanisms involved, it would appear to be relatively specific for MAIT cells, since the number of other innate-like lymphocytes, such as $\gamma \delta$-T cells and NKT cells, did not change in ICU patients of Grimaldi et al. [9].

This elegant study on a relatively large population of ICU patients adds MAIT cell depletion to the large puzzle of mechanisms leading to post-aggressive immunodepression. If further investigations are required to precisely identify the mechanism of such blood MAIT cell depletion. This can be seen as a potential attempt for using the number of MAIT cell in blood as a risk marker for secondary infection.

Conflicts of interest None. 


\section{References}

1. Dellinger RP, Levy MM, Rhodes A, Annane D, Gerlach H, Opal SM, Sevransky JE, Sprung CL, Douglas IS, Jaeschke R, Osborn TM, Nunnally ME, Townsend SR, Reinhart K, Kleinpell RM, Angus DC, Deutschman CS, Machado FR, Rubenfeld GD, Webb S, Beale RJ, Vincent JL, Moreno R (2013) Surviving sepsis campaign: international guidelines for management of severe sepsis and septic shock, 2012. Intensive Care Med 39:165-228

2. Hotchkiss RS, Monneret G, Payen D (2013) Immunosuppression in sepsis: a novel understanding of the disorder and a new therapeutic approach. Lancet Infect Dis 13:260-268

3. Boomer JS, To K, Chang KC, Takasu $\mathrm{O}$, Osborne DF, Walton AH, Bricker TL, Jarman SD 2nd, Kreisel D, Krupnick AS, Srivastava A, Swanson PE, Green JM, Hotchkiss RS (2011) Immunosuppression in patients who die of sepsis and multiple organ failure. JAMA 306:2594-2605

4. Docke WD, Randow F, Syrbe U, Krausch D, Asadullah K, Reinke P, Volk HD, Kox W (1997) Monocyte deactivation in septic patients: restoration by IFN-gamma treatment. Nat Med 3:678-681

5. Keh D, Boehnke T, Weber-Cartens S, Schulz C, Ahlers O, Bercker S, Volk HD, Doecke WD, Falke KJ, Gerlach H (2003) Immunologic and hemodynamic effects of "low-dose" hydrocortisone in septic shock: a double-blind, randomized, placebo-controlled, crossover study. Am J Respir Crit Care Med 167:512-520
6. Lukaszewicz AC, Grienay M, RescheRigon M, Pirracchio R, Faivre V, Boval B, Payen D (2009) Monocytic HLA-DR expression in intensive care patients: interest for prognosis and secondary infection prediction. Crit Care Med 37:2746-2752

7. Cuenca AG, Moldawer LL (2012) Myeloid-derived suppressor cells in sepsis: friend or foe? Intensive Care Med 38:928-930

8. Venet F, Chung CS, Kherouf H, Geeraert A, Malcus C, Poitevin F, Bohe J, Lepape A, Ayala A, Monneret G (2009) Increased circulating regulatory $\mathrm{T}$ cells $(\mathrm{CD} 4(+) \mathrm{CD} 25(+) \mathrm{CD} 127(-))$ contribute to lymphocyte anergy in septic shock patients. Intensive Care Med 35:678-686

9. Grimaldi D, Le Bourhis L, Sauneuf B, Dechartres A, Rousseau C, Ouaaz F, Milder M, Louis D, Chiche J, Mira J, Lantz O, Pène F (2013) Specific MAITcells behaviour among innate-like T-lymphocytes in critically ill patients with severe infections. Intensive Care Med. doi:10.1007/s00134-013-3163-x

10. Porcelli S, Yockey CE, Brenner MB, Balk SP (1993) Analysis of T cell antigen receptor (TCR) expression by human peripheral blood CD4-8- alpha/ beta $\mathrm{T}$ cells demonstrates preferential use of several $\mathrm{V}$ beta genes and an invariant TCR alpha chain. J Exp Med 178:1-16

11. Treiner E, Duban L, Bahram S, Radosavljevic M, Wanner V, Tilloy F, Affaticati P, Gilfillan S, Lantz O (2003) Selection of evolutionarily conserved mucosal-associated invariant $\mathrm{T}$ cells by MR1. Nature 422:164-169
12. Miyazaki Y, Miyake S, Chiba A, Lantz O, Yamamura T (2011) Mucosalassociated invariant $\mathrm{T}$ cells regulate Th1 response in multiple sclerosis. Int Immunol 23:529-535

13. Le Bourhis L, Martin E, Peguillet I, Guihot A, Froux N, Core M, Levy E, Dusseaux M, Meyssonnier V, Premel V, Ngo C, Riteau B, Duban L, Robert D, Huang S, Rottman M, Soudais C, Lantz O (2010) Antimicrobial activity of mucosal-associated invariant $\mathrm{T}$ cells. Nat Immunol 11:701-708

14. Gold MC, Lewinsohn DM (2013) Codependents: MR1-restricted MAIT cells and their antimicrobial function. Nat Rev Microbiol 11:14-19

15. Gold MC, Cerri S, Smyk-Pearson S, Cansler ME, Vogt TM, Delepine J, Winata E, Swarbrick GM, Chua WJ, Yu YY, Lantz O, Cook MS, Null MD, Jacoby DB, Harriff MJ, Lewinsohn DA, Hansen TH, Lewinsohn DM (2010) Human mucosal associated invariant $\mathrm{T}$ cells detect bacterially infected cells. PLoS Biol 8:e1000407

16. Le Bourhis L, Dusseaux M, Bohineust A, Bessoles S, Martin E, Premel V, Core M, Sleurs D, Serriari NE, Treiner E, Hivroz C, Sansonetti P, Gougeon ML, Soudais C, Lantz O (2013) MAIT cells detect and efficiently lyse bacterially-infected epithelial cells. PLoS Pathog 9:e1003681 